\title{
2. OBLIQUE-SCATTERING METHOD FOR MEASURING INDIVIDUAL RADIANTS AND METEOR VELOCITIES
}

\author{
N.S. Andrianov, R. A. Kurganov, A. M. Nasirov, V.V. Sidorov \\ (Radio Astronomy Observatory, Kazan, U.S.S.R.)
}

\section{Introduction}

In recent years, in addition to back-scatter radio methods of meteor studies, the oblique-scattering technique, earlier utilized for purposes of meteor radio-communication, has been more widely used. This has produced results, not only because of the availability of large quantities of experimental data obtained on numerous radiocommunication lines, but also due to certain advantages of this 'forward-scatter' technique.

Thus, Rice and Forsyth (1963) consider an advantage of oblique scattering the fact that the continuous-wave technique can be utilized, which guarantees an exact control of generator power and frequency, and considerably simplifies signal processing. Revah et al. (1964) believe that in the case of 'forward scattering' the accuracy of the reflection-point height measurements by the diffusion coefficient is increased due to the improvement of the amplitude-time curve. Rice and Forsyth (1963), making use of the pronounced diffraction variations of the oblique-scatter signal amplitude, have obtained the data on the relative variations along meteor trains. Andrianov (1965) pointed out that in the case of forward scatter a considerably greater number of reflections have diffraction patterns suitable for measuring meteor velocities.

Pavlov (1966) considered that in the case of oblique scattering resonance effects diminish considerably. To this we should like to add that not only the distorting influence of resonance, but also that of diffusion effects, diminish, which is vital for fast meteor-velocity measurements.

Finally, the most important point is that in the case of oblique scattering the effective wavelength increases by $\sec \varphi^{*}(2 \sim 10$ times $)$, and correspondingly decreases the attenuating effect of the initial radius. Taking this as a basis McKinley (1961) discussed the value of the oblique-scattering technique for the observation of faint fast meteors.

$* 2 \varphi=$ forward-scatter angle.

Kresák and Millman (eds.), Physics and Dynamics of Meteors, 14-26. (C I.A.U. 


\section{Individual Radiant and Meteor-Velocity Measurement by Oblique Scattering}

The measurement of the radiants and velocities of individual meteors by oblique scattering is made difficult by the complexity of the geometric situation, which can be overcome, however.

The measurement method (and the corresponding equipment) is described in the papers by Andrianov (1965), and Andrianov and Sidorov (1966). It amounts to the measurement of relative delays in the appearance of meteor reflections at three separate receiving stations, and the simultaneous measurement of the incident angles of a reflected signal at one of these points.

Such a measuring apparatus, 'KGU-M3', constructed at the Kazan University in 1964 on the basis of a latitudinal $100-\mathrm{km}$ radio-communication line, has the following characteristics:

(1) Wavelength $\lambda=7 \cdot 44 \mathrm{~m}$ (effective wavelength $22 \mathrm{~m}$ ).

(2) The transmitter, antennas, and receivers ensure the recording of trail reflections with a minimum electronic density

$$
\alpha_{\min }=10^{12} \text { electrons } / \mathrm{m}
$$

(3) Mean-root-square error in meteor-velocity measurements $\simeq 1.5 \mathrm{~km} / \mathrm{s}$.

(4) Mean-root-square error in meteor-radiant measurements $\simeq 2 \cdot 5^{\circ}$.

Because of the complexity of the analytical solution, the determination of resultant error dependence on the measured parameter errors was carried out by means of initial data variation and processing on a computer, using a special program for 225 meteors taken at random. The errors depend on the location of reflection points in the meteor zone, and have a maximum at $\psi=0$ and $\theta=15^{\circ}(\psi$ and $\theta$ are the azimuth and the angle of elevation respectively of the reflection point). Over the velocity range from $11-70 \mathrm{~km} / \mathrm{s}$ the errors increase $2 \cdot 5$ times. Checking several sets of observational results has confirmed our estimates. The main source of error in our case is the errors produced by the angle-gauge. By improving the observational technique it is possible to obtain better results in the case of oblique scattering than by employing the back-scatter method.

Wind errors will depend only on wind-velocity components perpendicular to the path. In the case of diurnal variations in wind direction the mean error will be less than in the back-scatter case. The errors caused by diffusion will be smaller because of a more favourable correlation between the rate of reflected signal-amplitude decay, and the time-scale of diffraction variations. As has already been pointed out, resonance effects are also reduced in the case of oblique scattering and, consequently, so are the errors connected with them.

Hence, it appears that the forward-scatter method is the most accurate among the 
radio methods of meteoric astronomy, but it depends on progress in the field of measuring the angle of incidence of the scattered signal.

To estimate the sensitivity of the measuring system for faint meteors, and to align it with the stellar value scale, it was necessary to obtain the minimum recorded electronic density $\alpha_{\min }$ at the characteristic altitude at the point of maximum ionization for a meteor of a given velocity. $\alpha_{\min }$ is a function of the technical characteristics of the considered radio system: $P, G, \Delta f, \lambda$ (generally accepted symbols). The radioreflection geometry also depends on the velocity, as well as on the diffusion coefficient and the initial radius at the characteristic height, which, in its turn, depends on velocity. The dependence of $\alpha_{\min }$ on $V$ ( $V=$ meteor velocity) was obtained in Andrianov's (1966) paper.

According to this paper the radio system in Kazan is capable of registering meteors brighter than $+10^{\mathrm{m}}$, moving at a velocity of $\simeq 11 \mathrm{~km} / \mathrm{s}$, and meteors brighter than $+7^{\mathrm{m}}$, moving at a velocity of $\simeq 70 \mathrm{~km} / \mathrm{s}$. Radio magnitudes rather than photographic ones are used here.

$$
M=35-2 \cdot 5 \log \alpha,
$$

which includes the photographic meteors only at $V=60 \mathrm{~km} / \mathrm{s}$.

Electronic density at the point of maximum ionization is

$$
\alpha \sim M V^{n},
$$

where $M$ is mass, and $n$ the power index, which we shall assume to be equal to 3 .

For a fixed velocity $V$ the probability of detecting a meteor with electronic density greater than $\alpha$ is:

$$
P_{v}(\alpha)=\int_{\alpha}^{\infty} P(\alpha) \mathrm{d} \alpha .
$$

Taking into consideration the power character of the meteor-mass distribution law $\left(P(m) \sim m^{-s}\right)$, utilizing Equation (2) for $s=2$ we obtain

$$
P_{v}(\alpha) \sim V_{\alpha}^{n} .
$$

If we take into account Equation (1), then for a fixed velocity the probability of recording a meteor brighter than a given stellar value

$$
P_{v}(M)=P_{v}(\alpha) \sim V^{n} e^{-\frac{M}{2 \cdot 5}} .
$$

Assuming $M=M_{\min }$ where $M_{\min }$ is the minimal recorded radio value related to $\alpha_{\min }$ by Equation (1), we obtain the probability of recording a meteor of a given velocity. If we take into account that $\alpha_{\min }$ also depends on velocity $V$, then considering $P_{v}\left[M_{\min }(V)\right]$ as a velocity function, we obtain the characteristic of our equipment's 


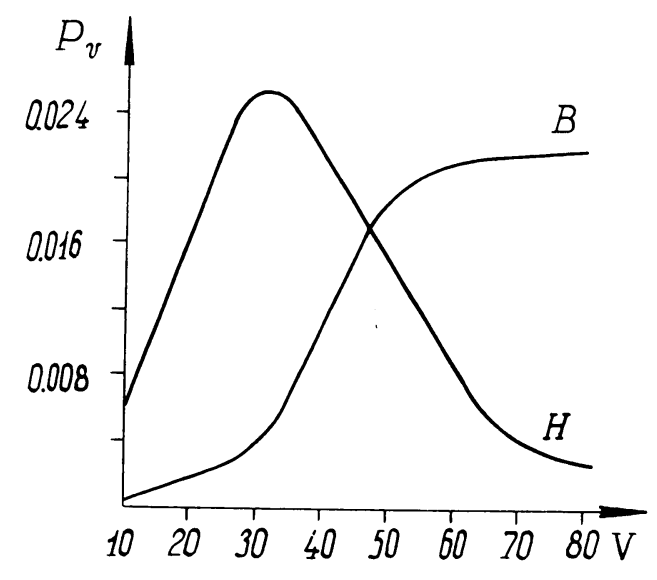

FIG. 1.

sensitivity for meteors of various speeds. It should be remembered that $\alpha_{\min }$ changes not only with velocity, but also with the change of a trail's orientation and its position in relation to the pattern of the aerial system.

Figure 1 shows this characteristic for two cases, oblique scattering $(B)$ at $\cos Z=\frac{2}{3}$, $s=2, n=3, \lambda=7.44 \mathrm{~m}, \alpha=10^{12} \mathrm{el} / \mathrm{m}$, and back-scatter $(H)$ with the same technical parameters. From Figure 1 we can see that if in the back-scatter case the probability of recording decreases with the transition to fast meteors, due to the weakening effect of the initial radius and diffusion, then in the case of oblique scattering the number of meteors registered with high velocities increases due to the greater coefficient of ionization. This graph illustrates the advantage of the oblique-scattering method in the observations of faint fast meteors.

It was necessary to evaluate the selectivity factors for the KGU-M3 station in order to interpret the observational results.

Similar to the method described by Davies and Gill (1960) and Lebedinec and Kaščeev (1966), we shall ascribe to each meteor weight $1 / P$ proportional to the product of weight factors:

$$
P=P_{1} P_{2} P_{3}
$$

$1 / P_{1}=$ physical factor allowing mainly for a velocity selection; $1 / P_{2}=$ geometric factor allowing for a difference in the observation of meteors with different inclinations; $1 / P_{3}=$ astronomical factor based on the probability of a meteor meeting with the Earth.

To obtain the physical factor we employed the method of Lebedinec and Kaščeev (1966).

In Table 1 are given the values of the physical factor $1 / P_{1}$ calculated for $\cos Z=\frac{2}{3}$, $\lambda=7 \cdot 44 \mathrm{~m}\left(\lambda_{\mathrm{ef}}=22 \mathrm{~m}\right), \alpha_{\min }=10^{12} \mathrm{el} / \mathrm{m}$. 
Table 1

$\begin{array}{ccccccccc}1 / P_{1} & 0.16 & 0.25 & 0.6 & 1 & 1.35 & 1.58 & 1.74 & 1.7 \\ V & 15 & 20 & 30 & 40 & 50 & 60 & 70 & 80\end{array}$

The geometric factor $P_{2}$ was calculated by the method suggested by Davies and Gill (1960), having as its basis around-the-clock observations of sporadic meteors. This factor, calculated for different inclinations, is given in Table 2.

\section{Table 2}

$\begin{array}{lcccccccccccc}P_{2} & 3 & 3.1 & 3.3 & 3.0 & 2.4 & 1.8 & 1.25 & 1 & 1.1 & 1.3 & 2.2 & 2 \\ \delta & -65^{\circ} & -55 & -45 & -35 & -25 & -15 & -5 & +5 & +15 & +25 & +35 & +45\end{array}$

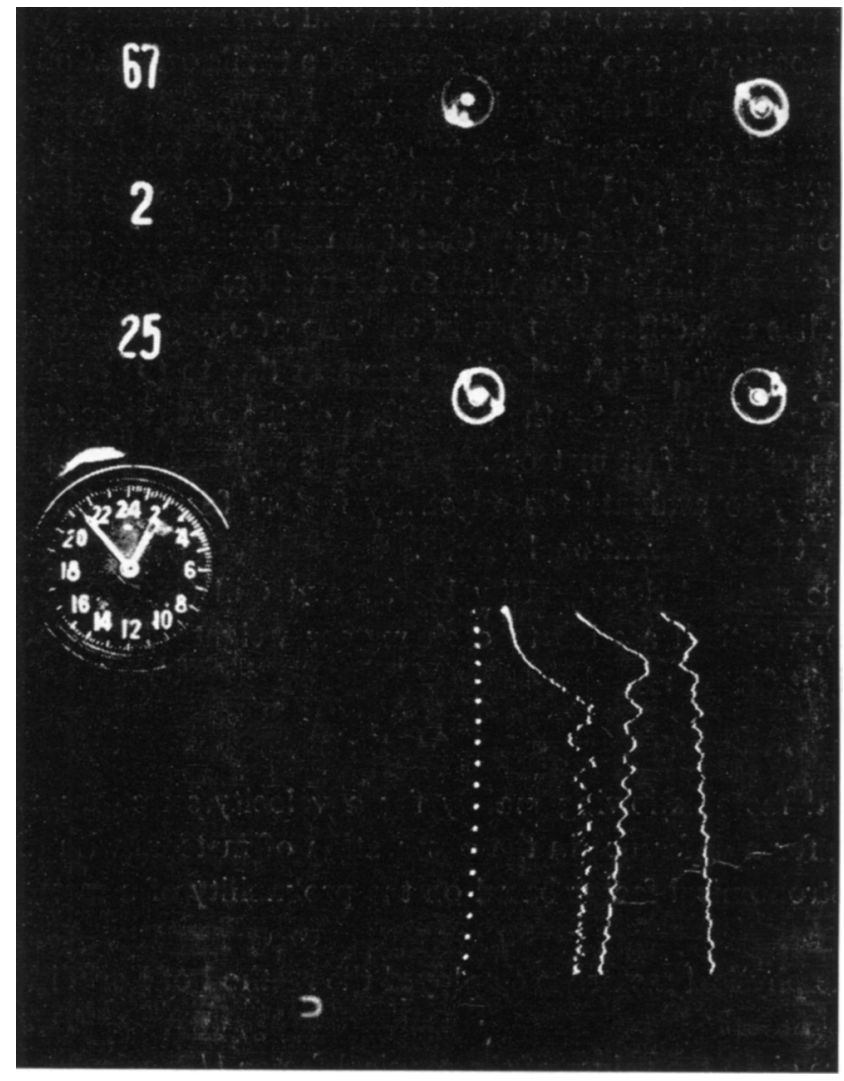

Fig. 2. 
The astronomical factor, as evaluated by Whipple (1954), is not affected by the peculiarities of the radio methods.

The KGU-M3 measuring station was set into operation in 1964 in Kazan. Meteorreflection parameters necessary for individual radiant measurements were recorded on photographic film.

An example of the photo record is given in Figure 2.

At first the measurements were sporadic, and it was not until October 1966 that a program of regular observations was adopted. By now 3200 meteor records have been processed.

\section{Measurement Results}

(a) Meteor distributions in ecliptic longitude. Figure 3 shows the distribution of the measured radiants in the coordinate $\lambda-\lambda_{\odot}\left(\lambda_{\odot}=\right.$ solar longitude) for each month from October to April. The distributions obtained are in good agreement with similar data contained in the papers by Davies and Gill (1960) and Lebedinec and Kaščeev (1966).

Figure 4 shows distributions for the same six months corrected for the physical and geometric factors. Three characteristic meteor concentrations towards the apex and $\pm 60^{\circ}$ from it are more clearly visible, which is in good agreement with observations by other authors.

(b) Meteor distributions in ecliptic latitude. Figure 5 shows, for the same six months, the distribution of radiants in ecliptic latitude. In Figure 6 these distributions are corrected, using Tables 1 and 2. A strong radiant concentration towards the ecliptic plane is evident, agreeing with Davies and Gill (1960), and Lebedinec and Kaščeev (1966). The degree of this concentration changes in the course of a year.

(c) Geocentric meteor-velocity distribution. Figure 7 shows the distribution of measured speeds, using the results of observations for six months. This distribution has one maximum in the vicinity of $25-30 \mathrm{~km} / \mathrm{s}$, and is in good agreement with the distribution obtained by Verniani et al. (1965). The maximum of the corrected distribution (Figure 8 ) is situated in the interval $15-20 \mathrm{~km} / \mathrm{s}$, in agreement with Lebedinec and Kaščeev (1966).

During the calculation of the physical factor it was assumed that ionization probability is directly proportional to the cube of the velocity. But, if ionization probability increases faster than $V^{3}$, an even greater displacement of the maximum towards low velocities is possible, when selection corrections are introduced.

Figure 9 (solid line) shows meteor-velocity distributions corrected for selection, for radiants situated on the celestial sphere inside concentric circles with the centre at the apex, and by angular steps $\Delta \varepsilon=10^{\circ}$, for elongation angles within the range of $0^{\circ}$ to $95^{\circ}$.

Similar distributions (dashed lines in Figure 9) were obtained for photographic meteor velocities, using the catalogue by McCrosky and Posen (1961). 

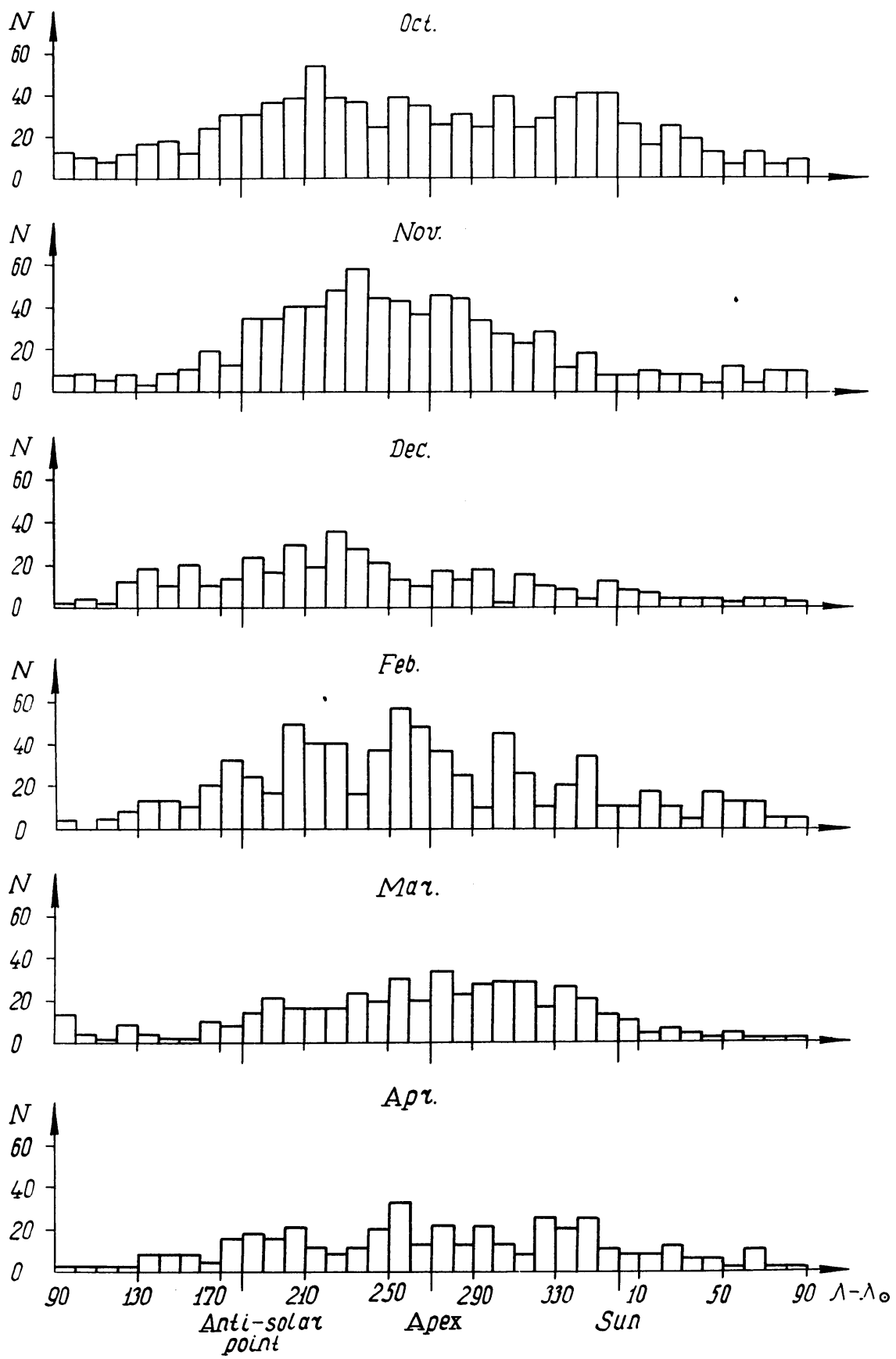

FIG. 3. 

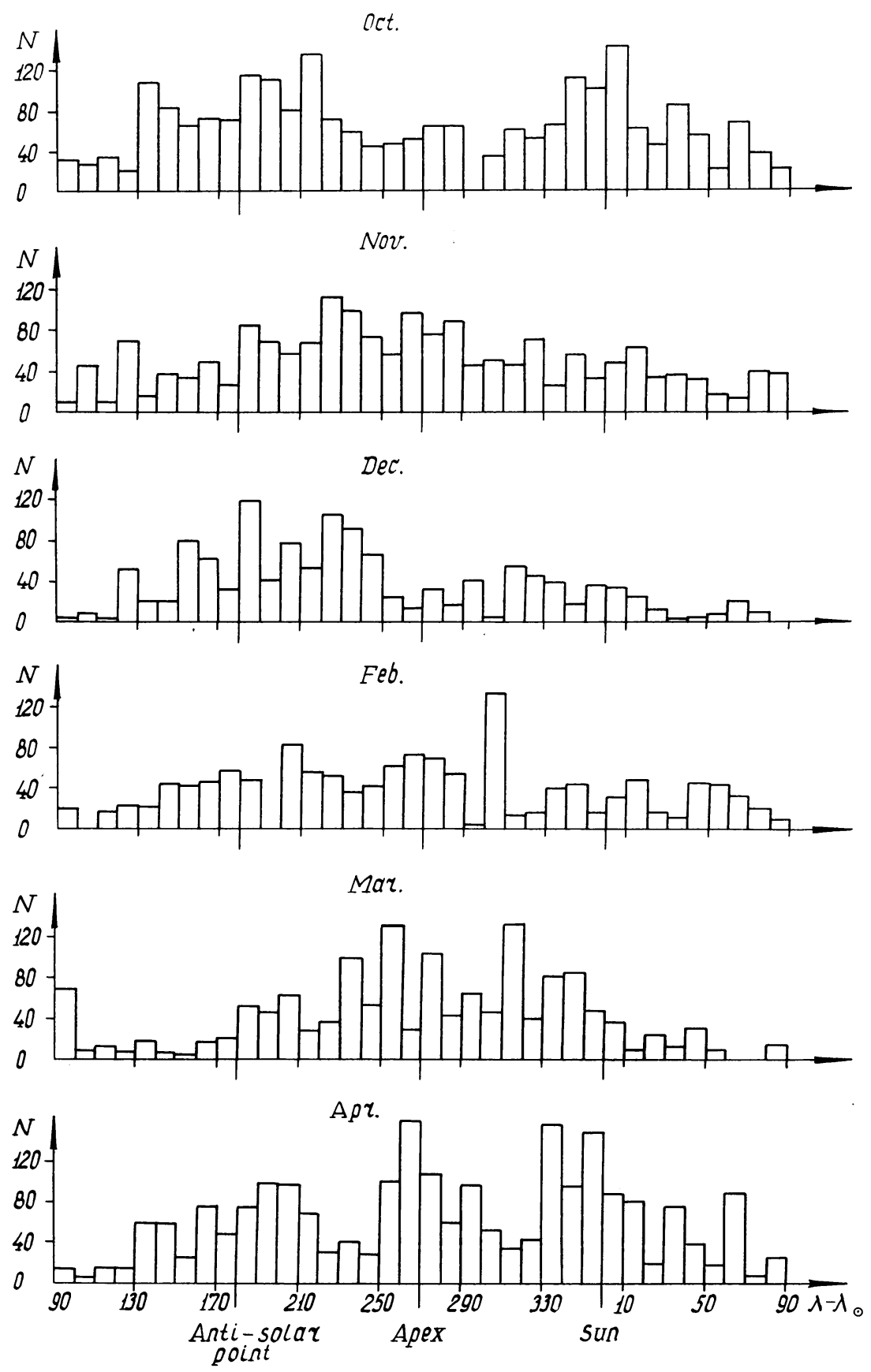

FIG. 4. 

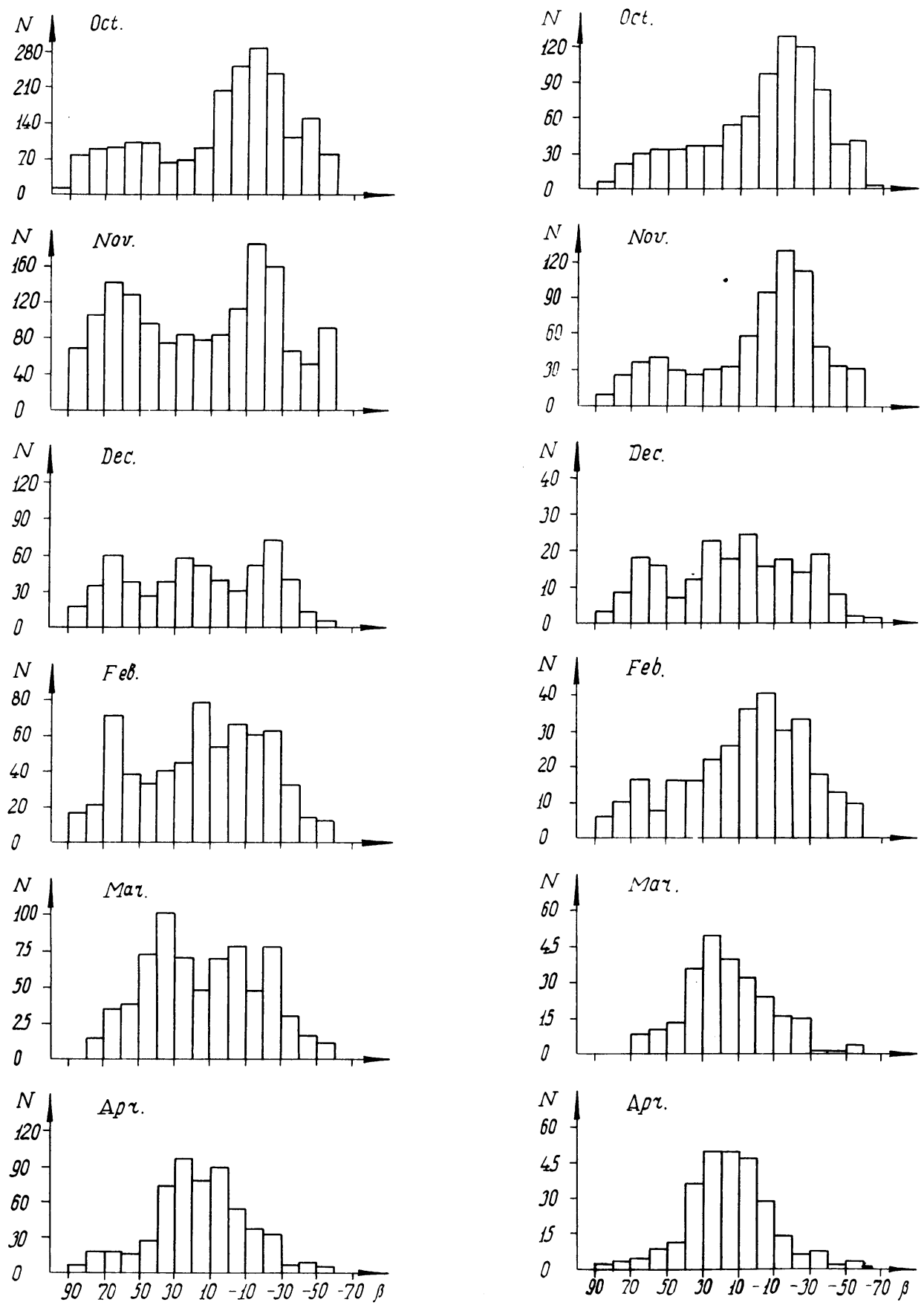

FIG. 5.
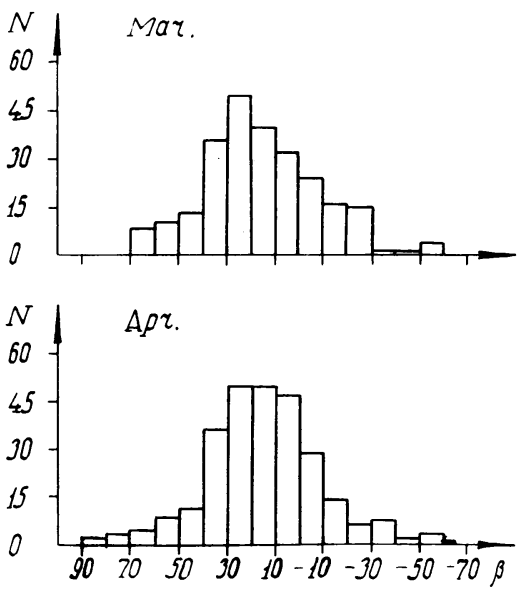

FIG. 6. 

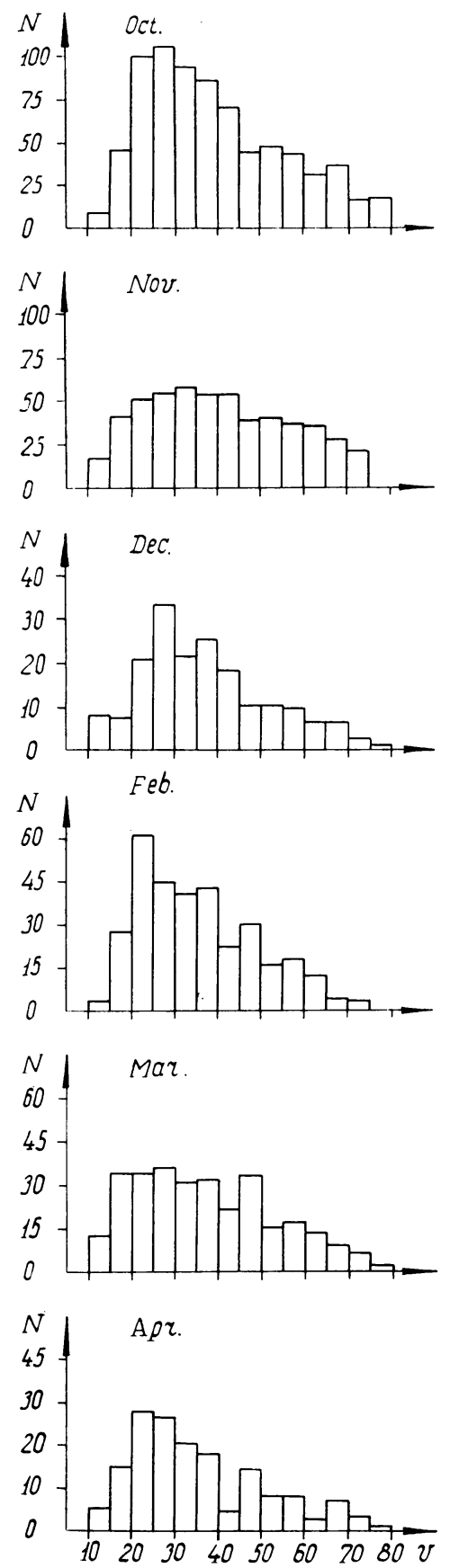

FIG. 7.
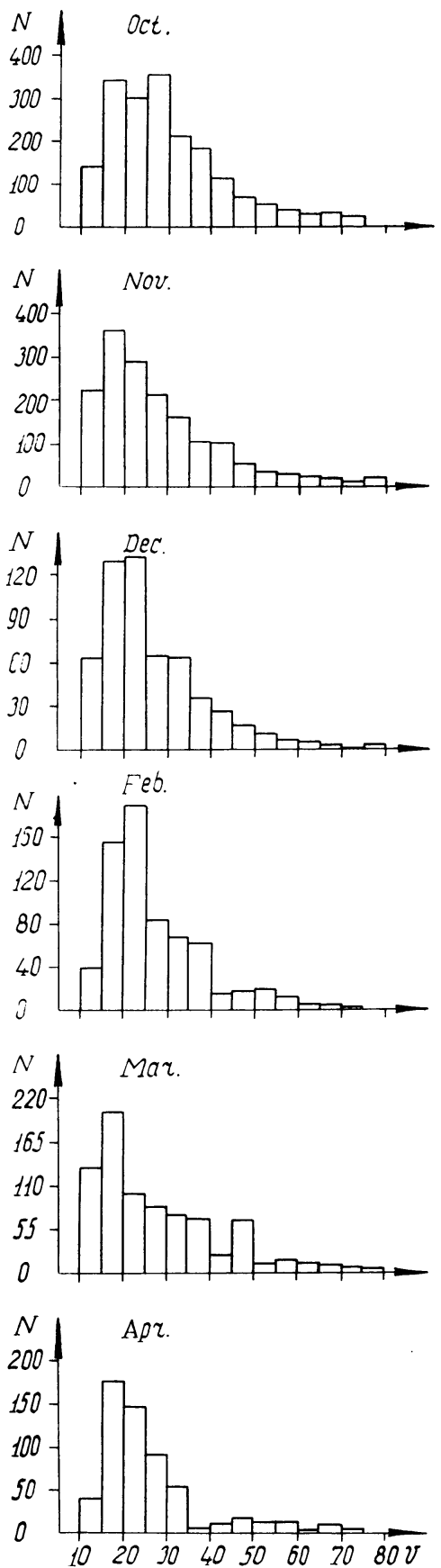

FIG. 8. 


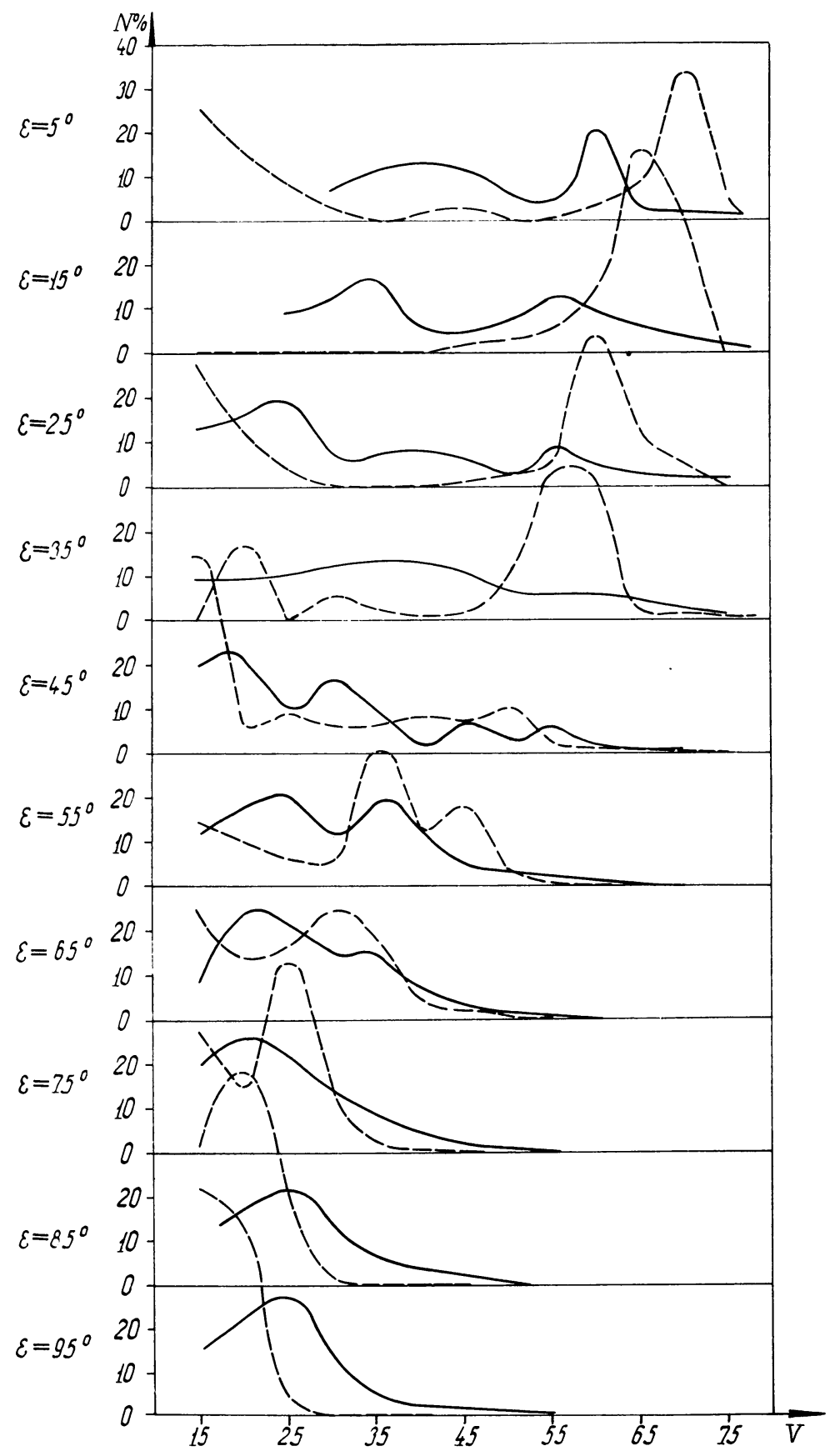

FIG. 9. 
For elongation less than $65^{\circ}$ both distributions have from 2-3 maxima; for elongations greater than $65^{\circ}$ distributions are one-humped. Radio and photographic distributions are very much alike, but in the photographic case the distance between the maxima is greater than in the radio case.

(d) Distribution of the incident meteor-flux density over the celestial sphere. To obtain a two-dimensional map of the relative density of the incident meteor flux, for masses greater than the limit set, a correction for the physical factor has been made for each meteor. The map grid is the same as in Pupyšev's (1966) work, i.e. the whole celestial sphere has been divided into equal areas 0.08 steradian each, in the co-ordinates $\lambda-\lambda_{\odot}, \beta$. The incident flux density has been assumed to be proportional to the meteor number registered in each section of the grid.

Such a map, made for October 1966 and based on 1200 measured radiants, is shown in Figure 10. Density figures are relative, given in terms of percentage of the

\begin{tabular}{|c|c|c|c|c|c|c|c|c|c|c|c|c|c|c|c|c|c|}
\hline \multirow{3}{*}{$\begin{array}{c}80^{\circ} \\
80^{\circ} \\
65^{\circ} \\
50^{\circ}\end{array}$} & \multicolumn{17}{|c|}{0.56} \\
\hline & & \multicolumn{3}{|c|}{$\begin{array}{l}0.85 \\
0.90 \\
\end{array}$} & \multicolumn{3}{|c|}{$\begin{array}{l}0.37 \\
0.34\end{array}$} & \multicolumn{3}{|c|}{$\begin{array}{l}0.66 \\
1.16\end{array}$} & \multicolumn{2}{|c|}{$\begin{array}{l}0.76 \\
1.50 \\
\end{array}$} & \multicolumn{3}{|c|}{$\begin{array}{l}0.80 \\
0.75\end{array}$} & \multirow{2}{*}{\multicolumn{2}{|c|}{\begin{tabular}{|l|}
1.13 \\
1.24 \\
0.44 \\
0.31
\end{tabular}}} \\
\hline & $\begin{array}{l}0.49 \\
0.59 \\
\end{array}$ & \multirow{2}{*}{\multicolumn{2}{|c|}{\begin{tabular}{|l|}
0.52 \\
0.33 \\
0.74 \\
0.16 \\
\end{tabular}}} & \multirow{2}{*}{\begin{tabular}{|l|}
0.46 \\
2.01 \\
0.60 \\
1.56 \\
\end{tabular}} & \multicolumn{2}{|c|}{$\begin{array}{l}0.44 \\
0.85\end{array}$} & $\begin{array}{l}0.42 \\
0.30\end{array}$ & $\begin{array}{l}0.51 \\
1.30\end{array}$ & \multicolumn{2}{|c|}{$\begin{array}{l}0.85 \\
1.81 \\
\end{array}$} & $\begin{array}{l}0.56 \\
0.56 \\
\end{array}$ & $\begin{array}{l}0.37 \\
1.22\end{array}$ & \multicolumn{2}{|c|}{$\begin{array}{l}0.27 \\
0.30\end{array}$} & \multirow{2}{*}{\begin{tabular}{|l|l|}
\multicolumn{1}{|c|}{$\begin{array}{l}0.46 \\
0.40\end{array}$} \\
$\begin{array}{l}0.40 \\
0.10\end{array}$ \\
\end{tabular}} & & \\
\hline & $\begin{array}{l}0.71 \\
0.06\end{array}$ & & & & $\begin{array}{l}0.57 \\
1.27\end{array}$ & $\begin{array}{l}0.40 \\
1.05\end{array}$ & $\begin{array}{l}0.41 \\
1.55\end{array}$ & $\begin{array}{l}0.49 \\
0.49\end{array}$ & $\begin{array}{l}0.48 \\
0.66\end{array}$ & $\begin{array}{l}0.48 \\
0.36\end{array}$ & $\begin{array}{l}0.40 \\
0.66\end{array}$ & $\begin{array}{l}0.26 \\
0.38 \\
\end{array}$ & $\begin{array}{l}0.40 \\
0.10 \\
\end{array}$ & $\begin{array}{l}0.83 \\
0.11 \\
\end{array}$ & & $\begin{array}{l}0.12 \\
0.07 \\
\end{array}$ & $\begin{array}{l}0.26 \\
0.67 \\
\end{array}$ \\
\hline & $\begin{array}{l}1.35 \\
0.03\end{array}$ & $\begin{array}{l}1.17 \\
0.15\end{array}$ & & $\begin{array}{l}1.00 \\
0.14\end{array}$ & $\begin{array}{l}0.30 \\
0.51\end{array}$ & $\begin{array}{l}0.57 \\
0.13\end{array}$ & $\begin{array}{l}0.32 \\
1.38\end{array}$ & $\begin{array}{l}0.50 \\
0.86\end{array}$ & $\begin{array}{l}0.66 \\
0.5\end{array}$ & $\begin{array}{l}0.46 \\
0.40\end{array}$ & $\begin{array}{l}0.42 \\
0.30\end{array}$ & $\begin{array}{l}0.44 \\
0.44\end{array}$ & $\begin{array}{l}0.55 \\
0.30\end{array}$ & $\begin{array}{l}0.57 \\
109\end{array}$ & $\begin{array}{l}0.39 \\
0.12\end{array}$ & $\begin{array}{l}0.16 \\
0.16\end{array}$ & $\begin{array}{l}0.46 \\
0.82\end{array}$ \\
\hline 60 & \begin{tabular}{|l|l}
0.76 & \\
0.55 & 0 \\
\end{tabular} & \begin{tabular}{|c|c|}
1.97 & 19 \\
0.08 & 0.3 \\
\end{tabular} & & \begin{tabular}{l|l}
63 & 214 \\
21 & 0.2
\end{tabular} & \begin{tabular}{l|l|l|}
14.01 \\
23 & 0.32 \\
\end{tabular} & \begin{tabular}{|l|l|l|}
0.83 & 0.5 \\
0.25 & 0.5
\end{tabular} & \begin{tabular}{l|l|l} 
\\
7.40 & 0.43 \\
999 & 0.83
\end{tabular} & \begin{tabular}{|l|l|l|l|l|l}
0.59 & 0 \\
0.40 & 0.
\end{tabular} & \begin{tabular}{|c|c|}
0.88 & 0.94 \\
0.52 & 0.4 \\
\end{tabular} & \begin{tabular}{|l|l}
0.72 & 0. \\
0.46 & 0. \\
\end{tabular} & \begin{tabular}{l|l|l}
0.41 & 0.46 \\
0.58 & 0.60
\end{tabular} & \begin{tabular}{|l|l|}
0.84 & 1 \\
0.72 & 1
\end{tabular} & \begin{tabular}{|l|l|}
1.18 & 0.91 \\
1.25 & 0.38 \\
\end{tabular} & \begin{tabular}{l|l}
1.42 & 1.0 \\
0.20 & 0.3
\end{tabular} & \begin{tabular}{l|l|}
0.09 & 0.79 \\
0.37 & 0.31
\end{tabular} & \begin{tabular}{|l|l}
0.06 & 0.2 \\
0.35 & 0.3
\end{tabular} & \begin{tabular}{l|l|}
0.20 & 0.20 \\
036 & 0.12
\end{tabular} \\
\hline U & \begin{tabular}{|l|}
0.18 \\
0.01 \\
\end{tabular} & \begin{tabular}{|l|l|}
1.23 & 5.4 \\
0.8 & 0.5 \\
\end{tabular} & & \begin{tabular}{l|l}
91 & 4.10 \\
78 & 0.7
\end{tabular} & \begin{tabular}{l|l|}
18 & 2.06 \\
72 & 0.89
\end{tabular} & \begin{tabular}{|l|l|}
0.99 & 0. \\
0.62 & 2. \\
\end{tabular} & & & \begin{tabular}{l|l|}
123 & 0.90 \\
124 & 0.57 \\
\end{tabular} & & \begin{tabular}{l|l}
0.82 & 0.36 \\
1.4 & 1.5 \\
\end{tabular} & $\begin{array}{l}0.73 \\
1.8\end{array}$ & \begin{tabular}{|l|l|}
1.53 & 0.55 \\
2.3 & 1.6 \\
\end{tabular} & $30^{\circ}$ & 0 & $60^{\circ}$ & $90^{\circ}$ \\
\hline-35 & 12 & $20^{\circ}$ & $\begin{array}{l}3 . \\
1 . \\
\end{array}$ & \begin{tabular}{l|}
80 \\
1
\end{tabular} & $\begin{array}{l}8.02 \\
1.85 \\
\end{array}$ & \begin{tabular}{|l|l|}
.22 \\
2.09 \\
\end{tabular} & $\begin{array}{l}0.71 \\
1.84 \\
\end{array}$ & $\begin{array}{l}0.78 \\
1.20 \\
\end{array}$ & $\begin{array}{l}0.60 \\
1.25 \\
\end{array}$ & \begin{tabular}{|l|}
0.91 \\
1.7 \\
\end{tabular} & \begin{tabular}{|l|l}
2.67 \\
1.6 \\
\end{tabular} & & $0^{\circ}$ & & & & \\
\hline $50^{\circ}$ & & & $150^{\circ}$ & 18 & & $\begin{array}{l}1.96 \\
1.18 \\
\end{array}$ & $\begin{array}{l}0.98 \\
0.57 \\
\end{array}$ & \begin{tabular}{|l|l|}
0.63 \\
0.62 \\
\end{tabular} & $\begin{array}{l}0.63 \\
0.8 \\
\end{array}$ & & & $\begin{array}{l}390^{\circ} \\
\lambda-\lambda_{0}\end{array}$ & & & & & \\
\hline & & & & & & & & & & & & & & & & & \\
\hline
\end{tabular}

Fig. 10.

total number of recorded meteors. For comparison, incident flux density values obtained by Pupyšev (1966) by the azimuthal statistical method for October 1965 are given in each section at the top.

The qualitative agreement of both maps can be seen. 


\section{Conclusions}

The above results show that the method of measuring individual radiants and meteor velocities evolved by us, which utilizes the oblique-scattering technique, is not inferior in accuracy to the radar method of Davies and Gill (1960), and is more sensitive to faint fast meteors. Although the amount of processed data is still insufficient to draw conclusions re the fine points in fast-meteor distribution, the distributions obtained by us testify to the fact that in the case of oblique scattering it is possible to surmount not only geometric complexities, but also the difficulties in the determination of selection factors.

An additional advantage of the oblique-scattering technique is, in our opinion, a considerable widening of the observed area of the celestial sphere in comparison with that observed with the help of a back-scatter radar.

\section{References}

Andrianov, N.S. (1965) Astr. Zu., 42, 679.

Andrianov, N.S. (1966) Meteornoe rasprostranenie radiovoln, Kazan, 3-4, 41.

Andrianov, N.S., Sidorov, V.V. (1966) Meteornoe rasprostranenie radiovoln, Kazan, 3-4, 36.

Davies, J.G., Gill, J.C. (1960) Mon. Not. R. astr. Soc., $121,437$.

Lebedinec, V.N., Kaščeev, B.L. (1966) Astr. Zu., 43, 854.

McCrosky, R.E., Posen, A. (1961) Smithson. Contr. Astrophys., 4, 15.

McKinley, D.W.R. (1961) Meteor Science and Engineering, McGraw-Hill, New York, 236.

Pavlov, A. F. (1966) Meteornoe rasprostranenie radiovoln, Kazan, 3-4, 159.

Pupyšev, J. A. (1966) Meteornoe rasprostranenie radiovoln, Kazan, 3-4, 5.

Revah, J., Spizzichino, A., Cohen, M. (1964) Ann. Télécommun., 19, 151.

Rice, D. W., Forsyth, P.A. (1963) Can. J. Phys., 41, 679.

Verniani, F., Hawkins, G., Southworth, R. (1965) Harvard Radio Meteor Project Rep., No. 12.

Whipple, F.L. (1954) Astr. J., 59, 201.

\section{DISCUSSION}

Kaiser: What is the significance of the high velocities (up to $90 \mathrm{~km} / \mathrm{s}$ ) in the tail of the velocity distribution?

Sidorov: Very low velocities $(v<10 \mathrm{~km} / \mathrm{s})$ and very high ones $(v>72 \mathrm{~km} / \mathrm{s})$ obviously result from insufficient accuracy in the velocity determination of individual meteors. 